\title{
Relationships between Substrate Promiscuity and Chiral Selectivity of Esterases from Phylogenetically and Environmentally Diverse Microorganisms
}

\author{
Cristina Coscolín ${ }^{1,+}$, Mónica Martínez-Martínez ${ }^{1,+}$, Jennifer Chow ${ }^{2}$, Rafael Bargiela ${ }^{1,3}$, \\ Antonio García-Moyano ${ }^{4}$ (D), Gro E. K. Bjerga ${ }^{4}$, Alexander Bollinger ${ }^{5}$ (D), Runar Stokke ${ }^{6}$, \\ Ida H. Steen ${ }^{6}$, Olga V. Golyshina 7,8, Michail M. Yakimov ${ }^{9,10}$, Karl-Erich Jaeger 5,11 (D), \\ Alexander F. Yakunin ${ }^{12}$, Wolfgang R. Streit ${ }^{2}$, Peter N. Golyshin ${ }^{7,8}$ and Manuel Ferrer ${ }^{1, *}$ \\ 1 Institute of Catalysis, Consejo Superior de Investigaciones Científicas, 28049 Madrid, Spain; \\ cristina.coscolin@csic.es (C.C.); m.martinez@csic.es (M.M.-M.); rafaelbb@icp.csic.es (R.B.) \\ 2 Biozentrum Klein Flottbek, Mikrobiologie \& Biotechnologie, Universität Hamburg, \\ 22609 Hamburg, Germany; jennifer.chow@uni-hamburg.de (J.C.); wolfgang.streit@uni-hamburg.de (W.R.S.) \\ 3 School of Chemistry, Bangor University, Bangor LL57 2UW, UK; f.bargiela@bangor.ac.uk \\ 4 Uni Research AS, Center for Applied Biotechnology, 5006 Bergen, Norway; \\ antonio.Moyano@uib.no (A.G.-M.); Gro.Bjerga@uni.no (G.E.K.B.) \\ 5 Institute of Molecular Enzyme Technology, Heinrich-Heine-University Düsseldorf, 52426 Jülich, Germany; \\ a.bollinger@fz-juelich.de (A.B.); k.-e.jaeger@fz-juelich.de (K.-E.J.) \\ 6 Department of Biology and KG Jebsen Centre for Deep Sea Research, University of Bergen, \\ 5020 Bergen, Norway; Runar.Stokke@uib.no (R.S.); Ida.Steen@uib.no (I.H.S.) \\ 7 School of Biological Sciences, Bangor University, LL57 2UW Bangor, UK; o.golyshina@bangor.ac.uk (O.V.G.); \\ p.golyshin@bangor.ac.uk (P.N.G.) \\ 8 Centre for Environmental Biotechnology, Bangor University, Bangor LL57 2UW, UK \\ 9 Institute for Coastal Marine Environment, Consiglio Nazionale delle Ricerche, 98122 Messina, Italy; \\ michail.yakimov@iamc.cnr.it \\ 10 Immanuel Kant Baltic Federal University, 236040 Kaliningrad, Russia \\ 11 Institute for Bio- and Geosciences IBG-1: Biotechnology, Forschungszentrum Jülich GmbH, 52426 Jülich, Germany \\ 12 Department of Chemical Engineering and Applied Chemistry, University of Toronto, \\ Toronto, ON M5S 3E5, Canada; a.iakounine@utoronto.ca \\ * Correspondence: mferrer@icp.csic.es; Tel.: +34-91-5854872 \\ + These authors contributed equally to this work.
}

Received: 22 December 2017; Accepted: 3 January 2018; Published: 5 January 2018

\begin{abstract}
Substrate specificity and selectivity of a biocatalyst are determined by the protein sequence and structure of its active site. Finding versatile biocatalysts acting against multiple substrates while at the same time being chiral selective is of interest for the pharmaceutical and chemical industry. However, the relationships between these two properties in natural microbial enzymes remain underexplored. Here, we performed an experimental analysis of substrate promiscuity and chiral selectivity in a set of 145 purified esterases from phylogenetically and environmentally diverse microorganisms, which were assayed against 96 diverse esters, 20 of which were enantiomers. Our results revealed a negative correlation between substrate promiscuity and chiral selectivity in the evaluated enzymes. Esterases displaying prominent substrate promiscuity and large catalytic environments are characterized by low chiral selectivity, a feature that has limited commercial value. Although a low level of substrate promiscuity does not guarantee high chiral selectivity, the probability that esterases with smaller active sites possess chiral selectivity factors of interest for industry (>25) is significantly higher than for promiscuous enzymes. Together, the present study unambiguously demonstrates that promiscuous and selective esterases appear to be rare in nature and that substrate promiscuity can be used as an indicator of the chiral selectivity level of esterases, and vice versa.
\end{abstract}

Keywords: esterase; metagenomics; promiscuity; selectivity 


\section{Introduction}

Presently, there is a great need for suitable biocatalysts with high process performance as greener alternatives to chemical synthesis [1,2]. It is expected that up to $40 \%$ of bulk chemical synthesis processes could be substituted by enzymatic catalysis by 2020 [1]. Along with requirements of a technical nature, such as process development and optimization, it is however widely recognized that the establishment of enzymatic processes is mainly a problem of finding, optimizing, or designing new and/or better performing enzymes. Nature is a rich reservoir from where enzymes can be isolated [3,4], because they are continuously evolving as a consequence of natural selection. Promiscuous enzymes are effective for converting multiple substrates, thus, they are industrially relevant [4-6]. Enzymes need to also be robust and, preferably, chiral selective to reduce raw material costs in the synthesis of pure chiral compounds $[1,2,4,7]$. That is, they need to be able to cleave preferentially only one chiral ester when offered a racemic mixture. Is it possible to find versatile enzymes displaying prominent substrate range and stringent chiral selectivity? Evaluating this possibility was the starting point of the present study.

In this study, we are interested in investigating as model enzymes serine ester hydrolases, hereafter referred to as esterases, from the structural superfamily of $\alpha / \beta$-hydrolases. The activity of these esterases relies mainly on a catalytic triad usually formed by Ser, Asp/Glu, and His [8]. This enzyme class was selected for a number of reasons: it is widely distributed in the environment, it has important physiological functions, it includes hydrolases that are among the most important industrial biocatalysts, and extensive biochemical knowledge has been accumulated $[4,5,7]$.

Just focusing on those from uncultivated microorganisms discovered through metagenomic approaches, esterases with prominent chiral selectivity have been identified and their use in the kinetic resolution of a number of esters is reported. Recent examples include those preferably hydrolyzing one of the chiral esters in racemic mixtures of ibuprofen esters [9,10]; ketoprofen esters [11-14]; solketal esters [15]; esters of phenylalkyl carboxylic acids, 1,1,1-trifluoro-2-phenylbut-3-yn-2-yl acetate and 3,7-dimethyl-1,6-octadien-3-yl acetate [16,17]; methyl 3-phenylglycidate [18]; 1-phenylethyl acetate [19,20]; ofloxacin butyl ester [21]; 1-octin-3-ol, 3-chlor-1-phenyl-1-propanol, trimethylsilylbutinol, cis/trans-1,2-cyclohexanediol, and isopropylidenglycerol acetate [22]; glycidyl butyrate [23]; methyl-mandelate, glycidyl-4-nitrobenzoate, methyl-3-bromo-2-methyl propionate, methyl lactate, menthyl acetate, neomenthyl acetate, pantolactone, and methyl 3-hydroxybutyrate [22,24,25]; 1-octin-3-ol, 3-chlor-1-phenyl-1-propanol, and trimethylsilylbutinol [22]; methyl-3-hydroxy-2-methylpropionate [26]; and esters of secondary alcohols $[27,28]$, to cite some. The advances in metagenomics techniques and screening methods have allowed the discovery of these and other selective esterases [29]. These studies exemplify that esterases with selective character occur naturally, and that their chiral preference depend on structural factors in the proximity of the active-site. However, whether the selective character of these esterases, and many others, is linked to a broad or a narrow substrate spectrum has not been investigated, due to limited substrate sets employed.

Here, we investigate the relationships between the level of substrate promiscuity and chiral selectivity of a large set of 145 phylogenetically and environmentally diverse microbial esterases, whose specific activity against 96 distinct esters that included 20 chiral esters have been recently reported [5]. We provide unambiguous experimental evidence suggesting a negative association between substrate specificity and chiral selectivity in native esterases.

\section{Results and Discussion}

\subsection{Relationships between Substrate Promiscuity and Chiral Selectivity}

We have recently described an extensive analysis of the substrate spectra of 145 phylogenetically and environmentally diverse microbial esterases [5]. Experimental data on substrate conversion (i.e., units $\mathrm{g}^{-1}$ or $\mathrm{U} \cdot \mathrm{g}^{-1}$ ) followed for $24 \mathrm{~h}$, at $\mathrm{pH} 8.0$ and $30^{\circ} \mathrm{C}$ was reported for 96 distinct esters. They included esters with variation in size of acyl and alcohol groups and with growing residues (aromatic, aliphatic, branched, and unbranched), halogenated esters, sugar esters, lactones, an alkyl 
di-ester, and 20 chiral esters (including $(R)$ and $(S)$ enantiomers of menthyl acetate, $N$-benzyl-proline ethyl ester, methyl mandelate, ethyl 4-chloro-3-hydroxybutyrate, methyl 3-hydroxybutyrate, methyl 3-hydroxyvalerate, neomenthyl acetate, methyl and ethyl lactate, and pantolactone). By meaning of the partitioning coefficient ( $\log p$ value), which reflects electronic and steric effects and hydrophobic and hydrophilic characteristics, the 96 esters do show a broad chemical and structural variability [5]. This chemical variability also characterized the chiral esters tested (Figure 1).

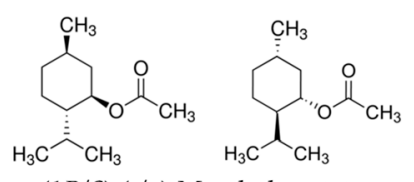

$(1 R / S)-(-/+)-M e n t h y l$ acetate
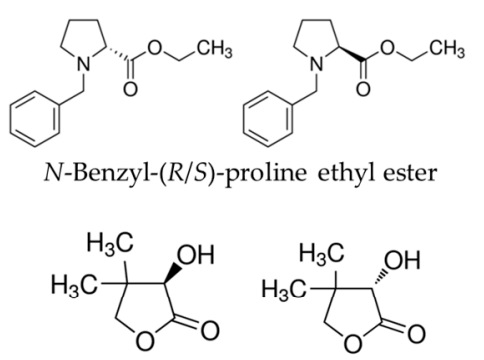

$(R / S)-(-/+)$-Pantolactone<smiles>CCOC(=O)CC(O)CCl</smiles>

Ethyl $(R / S)$-4-chloro-3-hydroxybutyrate<smiles>CCOC(=O)[C@H](C)O</smiles>

(+/-)-Ethyl $(R / S)$-lactate
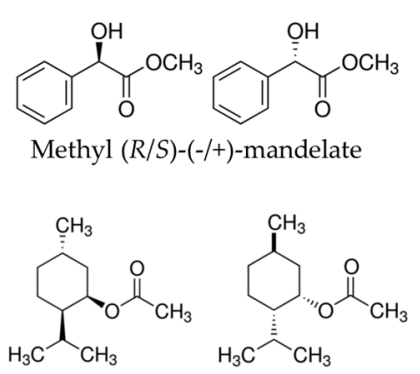

$(1 R / S)-(-/+)-N e o m e n t h y l$ acetate<smiles>CC[C@H](O)CC(=O)OC</smiles>

(-/+)-Methyl (R/S)-3-hydroxyvalerate<smiles>COC(=O)C[C@@H](C)O</smiles>

(-/+)-Methyl (R/S)-3-hydroxybutyrate<smiles>COC(=O)[C@H](C)O</smiles>

(+/-)-Methyl (R/S)-lactate

Figure 1. Representative chemical structures of 20 chiral esters used to evaluate chiral selectivity.

To find the relationships between substrate promiscuity and chiral selectivity we calculated the chiral selectivity factor for each of the 145 esterases and the 20 chiral esters tested (i.e., two enantiomers per pair) that were included in the 96-ester library (Figure 1). Selectivity factor was calculated as the ratio of specific activity $\left(\mathrm{U} \cdot \mathrm{g}^{-1}\right)$ of the preferred over the non-preferred chiral ester when both esters were tested separately [30] (see Materials and Methods). These calculations were extracted from datasets reported previously [5]. It should be mentioned that these apparent values may not correspond to true selectivity or enantiomeric factors calculated when the enzyme is confronted to a racemic mixture, because the rates of hydrolysis of the enantiomers were measured separately [30]; nevertheless, recent studies have clearly demonstrated that apparent and true selectivity values closely match each other [15]. These values were plotted against the number of esters hydrolyzed by each of the esterases (Figure 2), previously reported for each of the esterases [5].

From the 145 esterases, 40 did not show appreciable activity under assay conditions for any of the chiral esters tested. From those being active against at least one of the chiral esters (105 in total), 80 esterases were characterized by selectivity factors below a threshold of 25 . Although esterases with stringent selectivity are preferred, it is commonly considered that enzymes with selectivity factor of 25 or above begin to have commercial value [31]. On the other hand, we found 25 chiral selective esterases, as judged by a selectivity factor above 25 (Figures 2 and 3). Ten of them showed stringent selectivity, that is they were capable of hydrolyzing only one of the enantiomer (Figure 3). Twelve of 
them were characterized by selectivity factors ranging from 25.9 to 59.3 , and three did show prominent selectivity factors ranging from 219 to 686 (Figures 2 and 3).

As shown in Figure 2, we found a negative association between the level of substrate promiscuity, by meaning of the number of esters hydrolyzed, and the chiral selectivity factor. In further detail, according to criteria previously established [5] we considered an esterase 'specific' if it hydrolyses 9 esters or fewer, as 'moderate-to-highly promiscuous' if it hydrolyses between 10 and 42 esters, and as 'prominently promiscuous' if it hydrolyses 42 or more esters. None of the 25 hydrolases which showed a selectivity factor $\geq 25$ were prominently promiscuous. Rather, they were capable of accepting 36 or fewer substrates. However, not all hydrolases converting 36 or fewer esters and acting against chiral esters were selective according to the 25-selective factor threshold. Indeed, only 25 out of 85 in total (or 29\%) were selective, with different selectivity factors and chiral preferences (Figure 3). This is most likely due to the fact that the ability to selectively hydrolyze an enantiomer in a racemate may depend on the topology of the catalytic environment [5].

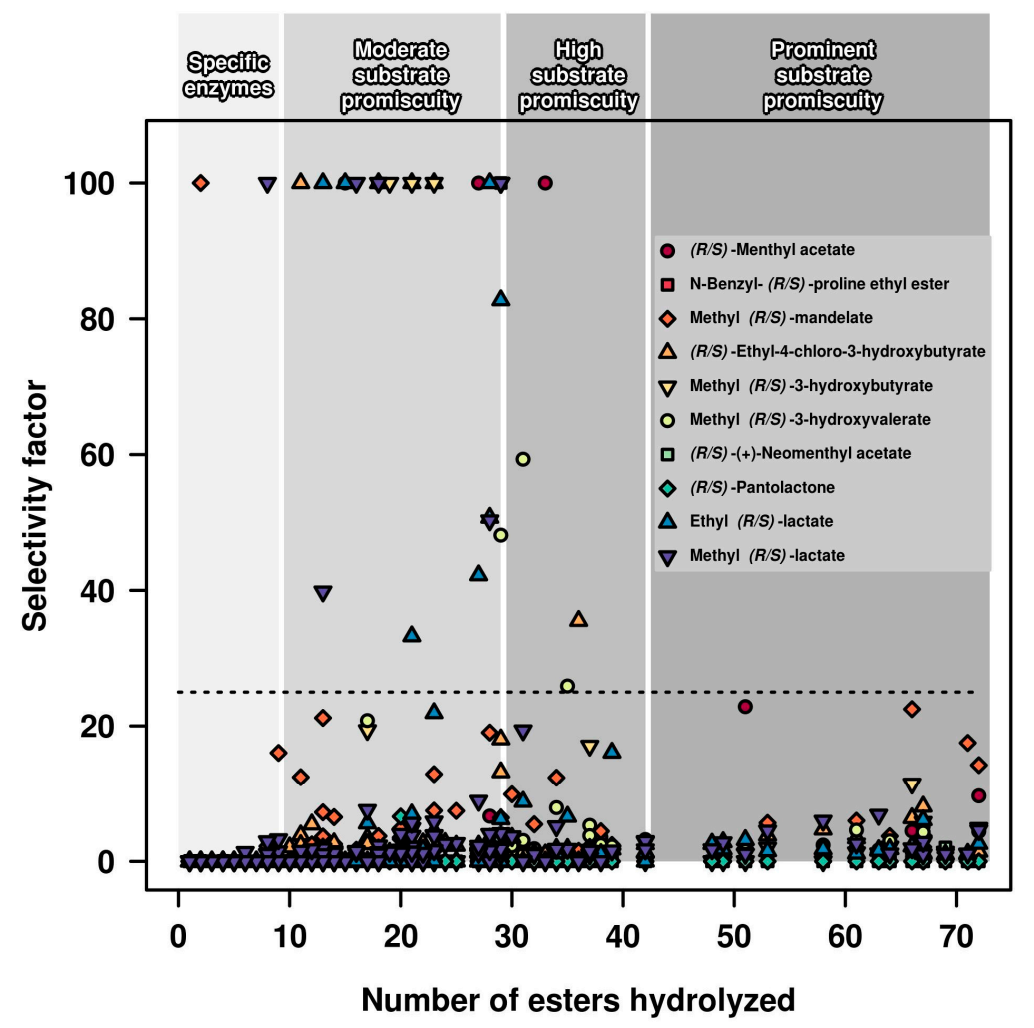

Figure 2. Chiral selectivity factor vs. number of esters hydrolyzed per each of the 145 hydrolases tested. Selectivity factor was calculated per each pair of enantiomers as the ratio of specific activity $\left(\mathrm{U} \cdot \mathrm{g}^{-1}\right)$ of the preferred over the non-preferred chiral ester when each of the chiral esters was tested separately. Chiral esters are color coded. The value 100 was arbitrarily given to represent those esterases capable of hydrolyzing, under our assay conditions, only one of the enantiomers (100\% selective) and those with selectivity factors higher than 100. These data are based on the data reported previously [5], using conditions described in Materials and Methods. The level of promiscuity, according to criteria previously established [5], is marked under a shadowed grey background. The 25-selectivity factor threshold at which an esterase started to have commercial value is indicated by a horizontal dashed gray line. 


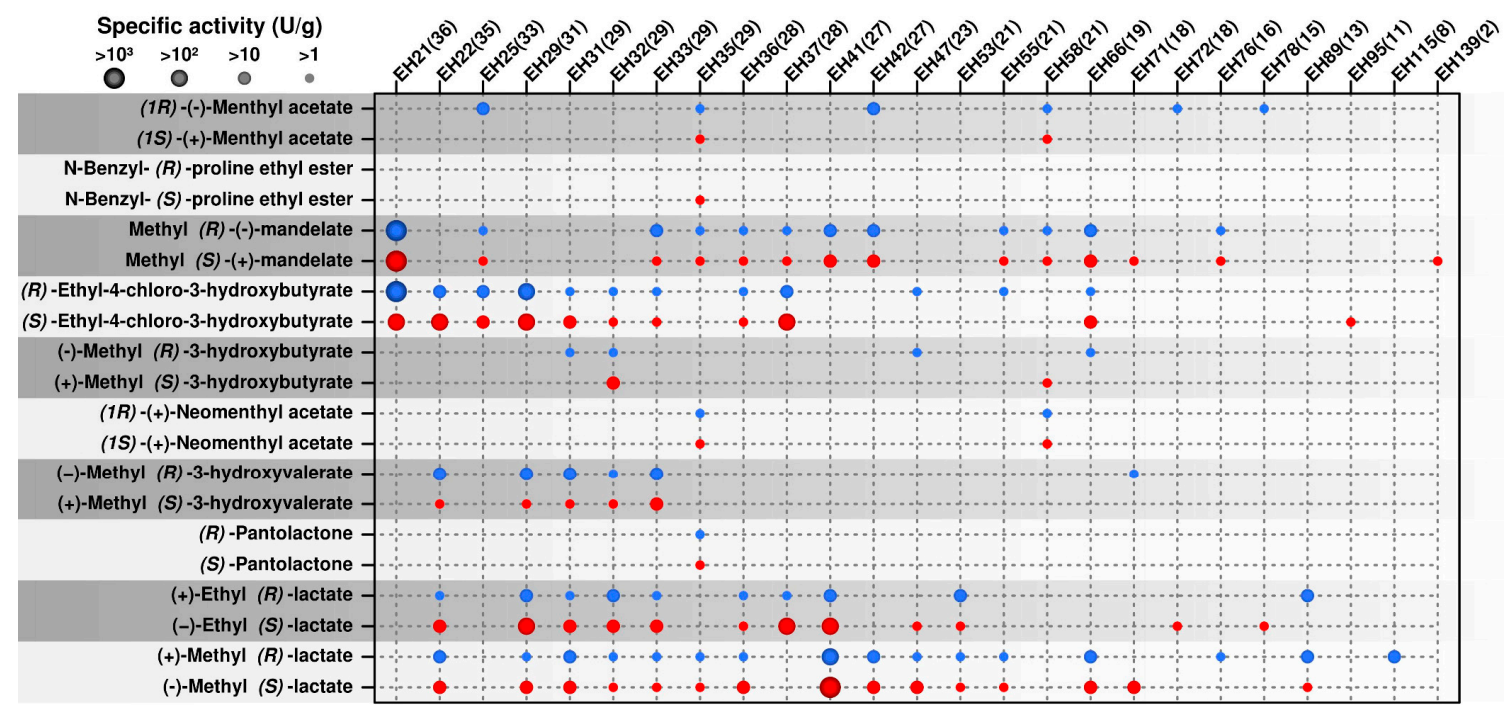

Figure 3. Chiral preferences of 25 hydrolases which were found to be selective for at least one chiral ester according to the 25-selective factor threshold. The figure illustrates the specific activity ( $\mathrm{U} \cdot \mathrm{g}^{-1}$; represented by the size of the circles) of each esterase per each of the 20 chiral esters tested. The ID code for each esterase (for full description see ref. [5]) is shown on the top; the number of esters (out of 96 tested) hydrolyzed by each esterase is shown in brackets. The Figure was created with the $\mathrm{R}$ language console from data previously reported [5]. The list of the 20 chiral esters tested is shown on the left, with $(R)$-enantiomer in blue and $(S)$-enantiomer in red color. The protocol established and used to identify the esters hydrolyzed by each esterase is described in Materials and Methods.

\subsection{Occurrence of Multi Selective Esterases}

Figure 3 summarizes the chiral preference of esterases fitting to the 25-selective factor threshold for each of the 20 chiral esters tested. As can be seen in Figure 3, esterases showed different level of promiscuity and preference for $(R)$ or $(S)$ methyl acetate, menthyl mandelate, methyl 3-hydroxybutyrate, $N$-benzyl-proline ethyl ester, ethyl-4-chloro-3-hydroxybutyrate, and (m)ethyl lactate. Esterases selective for $(R)$ or $(S)$-pantolactone, $N$-benzyl-proline ethyl ester, and neomenthyl acetate were the least abundant, suggesting these chiral esters are less preferred substrates. As shown in Figure 3, we also found that 5 out of 25 esterases fitting to the 25-selective threshold did show stringent selectivity or selectivity factor higher than 25 for several chiral esters differing in chemical and structural nature. They include one being selective for methyl 3-hydroxybutyrate ( $R$-selective) and ethyl lactate (S-preference) (EH31); one for ethyl-4-chloro-3-hydroxybutyrate ( $R$-selective), methyl 3-hydroxybutyrate ( $R$-selective), and ethyl lactate (S-selective) (EH47); one for methyl mandelate (S-selective), methyl 3-hydroxyvalerate ( $S$-selective) and methyl lactate (S-selective) (EH71); and two for menthyl acetate ( $R$-selective) and methyl lactate ( $S$-selective) (EH72 and EH78). The other 20 esterases did show the capacity to preferentially hydrolyze only one enantiomer (Figure 3). This suggests that multi selective esterases may have a lower abundancy.

\section{Materials and Methods}

\subsection{Source of Chemicals, Enzymes, and Datasets}

All chemicals for which activity data are reported were of the purest grade available and were purchased as reported [5]. The present study used datasets of hydrolytic activity $\left(\mathrm{U} \cdot \mathrm{g}^{-1}\right)$ for 145 esterases assayed at $550 \mathrm{~nm}$ using 96-structurally diverse esters in 384-well plates. Reactions were followed for $24 \mathrm{~h}$, at $\mathrm{pH} 8.0$ and $30^{\circ} \mathrm{C}$. Datasets are available elsewhere [5]. 


\subsection{Selectivity Factor Calculation}

The chiral selectivity factor is defined as the ratio of the specific activity [30] for each enantiomer, measured separately as described previously [5]. Briefly, reaction mixture contains $5 \mathrm{mM} \mathrm{N}$-(2-hydroxyethyl)piperazine- $N^{\prime}$-(3-propanesulfonic acid buffer, $\mathrm{pH} 8.0,4.5 \%(v / v)$ acetonitrile or dimethyl sulfoxide, $0.45 \mathrm{mM}$ Phenol Red (used as a $\mathrm{pH}$ indicator), a concentration of each of the esters of $1.14 \mathrm{mg} \cdot \mathrm{mL}^{-1}$, and $2 \mu \mathrm{g}$ of proteins. Reactions were allowed to proceed kinetically at $30^{\circ} \mathrm{C}$ and hydrolytic activity $\left(\mathrm{U} \cdot \mathrm{g}^{-1}\right)$ calculated followed for $24 \mathrm{~h}$ [5]. Selectivity factor was calculated considering the preferred over the non-preferred chiral ester, whatever the preferred $(R)$ or $(S)$ ester.

\section{Conclusions}

Herein, we show the value of the systematic investigation of enzyme activity to deepen our understanding of the relationships between substrate promiscuity and chiral selectivity. By comparing the number of esters that 145 diverse esterases hydrolyze as an indicator of the substrate promiscuity level and their selectivity factors as an indicator of enantio-selectivity, we found unambiguous evidence that esterases with broad substrate spectra do commonly show low selectivity for chiral molecules. In this study, the proportion of esterases with both prominent promiscuity and selectivity approaches zero percent. By contrast, the proportion of esterases with low to moderate promiscuity but prominent selectivity was as high as $29 \%$. This suggests that the substrate promiscuity may be used as an indicator of the selective character of esterases. Promiscuous esterases acting against multiple substrates, while at the same time being enantio-selective, appear to be rare in nature, or at least in the habitats from where the esterases herein described were isolated [5]. As these enzymes are of interest for application purposes [1-6,32], protein engineering and rational design may be needed to obtain esterases being promiscuous and selective for industrial applications. We anticipate that the possibility to transform a promiscuous but not selective esterase into an efficient enantio-selective biocatalyst would require less engineering effort because increasing the selectivity for an enantiomer may involve a reduced number of contacts close to the active sites (for a recent example see reference [33]). Conversely, increasing the substrate spectra of a selective non-promiscuous esterase would require large rearrangement of the catalytic environment which may, at the same time, result in significant reduction or even loss of enantio-selectivity. This is because non-promiscuous esterases are characterized by catalytic environments that are highly exposed and have small volumes, while an esterase for being promiscuous requires a large active site volume and lower relative solvent accessible surface area [5], that are difficult to be designed through few mutations.

Acknowledgments: This project has received funding from the European Union's Horizon 2020 research and innovation program (Blue Growth: Unlocking the potential of Seas and Oceans) through the Project 'INMARE' under grant agreement No. 634486 and ERA-IB 5 'METACAT'. This work was further funded by grants PCIN-2014-107 (within ERA NET IB2 grant nr. ERA-IB-14-030-MetaCat), PCIN-2017-078 (within the ERA-MarineBiotech grant ProBone), BIO2014-54494-R and BIO2017-85522-R from the Spanish Ministry of Economy and Competitiveness. The present investigation was also funded by the UK Biotechnology and Biological Sciences Research Council (BBSRC), grant nr. BB/M029085/1. P.N.G. acknowledges the support of the Supercomputing Wales project, which is partly funded by the European Regional Development Fund (ERDF) via the Welsh Government. O.V.G. and P.N.G. acknowledge the support of the Centre of Environmental Biotechnology Project funded by the European Regional Development Fund (ERDF) through the Welsh Government. A.F.Y. gratefully acknowledges funding from Genome Canada (2009-OGI-ABC-1405) and the NSERC Strategic Network grant IBN. The authors gratefully acknowledge financial support provided by the European Regional Development Fund (ERDF). C. Coscolín thanks the Spanish Ministry of Economy, Industry and Competitiveness for a PhD fellowship (Grant BES-2015-073829).

Author Contributions: M.F., P.N.G., and W.R.S. conceived the study; C.C., M.M.-M., J.C., R.B., A.G.-M., G.E.K.B., A.B., R.S., I.H.S., O.V.G., M.M.Y., K.-E.J. and A.F.Y. contributed to enzyme collection and data analysis; M.F. drafted the manuscript which was revised by all co-authors.

Conflicts of Interest: The authors declare no conflict of interest. The founding sponsors had no role in the design of the study; in the collection, analyses, or interpretation of data; in the writing of the manuscript, or in the decision to publish the results. 


\section{References}

1. Martínez-Martínez, M.; Bargiela, R.; Ferrer, M. Metagenomics and the search for industrial enzymes. In Biotechnology of Microbial Enzymes, 1st ed.; Brahmachari, G., Demain, A.L., Adrio, J.L., Eds.; Academic Press: Chennai, India, 2015; pp. 167-184.

2. Martínez-Martínez, M.; Bargiela, R.; Coscolín, C.; Navarro-Fernández, J.; Golyshin, P.N.; Ferrer, M. Functionalization and modification of hydrocarbon-like molecules guided by metagenomics: Enzymes most requested at the industrial scale for chemical synthesis as study cases. In Consequences of Microbial Interactions with Hydrocarbons, Oils, and Lipids: Production of Fuels and Chemicals; Lee, S.Y., Ed.; Springer International Publishing AG: Cham, Switzerland, 2016; pp. 1-26.

3. Yarza, P.; Yilmaz, P.; Pruesse, E.; Glöckner, F.O.; Ludwig, W.; Schleifer, K.H.; Whitman, W.B.; Euzéby, J.; Amann, R.; Rosselló-Móra, R. Uniting the classification of cultured and uncultured bacteria and archaea using 16S rRNA gene sequences. Nat. Rev. Microbiol. 2014, 12, 635-645. [CrossRef] [PubMed]

4. Ferrer, M.; Martínez-Martínez, M.; Bargiela, R.; Streit, W.R.; Golyshina, O.V.; Golyshin, P.N. Estimating the success of enzyme bioprospecting through metagenomics: Current status and future trends. Microb. Biotechnol. 2016, 9, 22-34. [CrossRef] [PubMed]

5. Martínez-Martínez, M.; Coscolín, C.; Santiago, G.; Chow, J.; Stogios, P.; Bargiela, R.; Gertler, C.; Navarro-Fernández, J.; Bollinger, A.; Thies, S.; et al. Determinants and prediction of esterase substrate promiscuity patterns. ACS Chem. Biol. 2017. [CrossRef] [PubMed]

6. Schmid, A.; Dordick, J.S.; Hauer, B.; Kiener, A.; Wubbolts, M.; Witholt, B. Industrial biocatalysis today and tomorrow. Nature 2001, 409, 258-268. [CrossRef] [PubMed]

7. Ferrer, M.; Bargiela, R.; Martínez-Martínez, M.; Mir, J.; Koch, R.; Golyshina, O.V.; Golyshin, P.N. Biodiversity for Biocatalysis: A review for $\alpha / \beta$-hydrolases of the esterase-lipase superfamily as case of Study. Biocatal. Biotransform. 2015, 33, 235-249. [CrossRef]

8. Aranda, J.; Cerqueira, N.M.; Fernandes, P.A.; Roca, M.; Tuñon, I.; Ramos, M.J. The Catalytic Mechanism of Carboxylesterases: A Computational Study. Biochemistry 2014, 53, 5820-5829. [PubMed]

9. Elend, C.; Schmeisser, C.; Hoebenreich, H.; Steele, H.L.; Streit, W.R. Isolation and characterization of a metagenome-derived and cold-active lipase with high stereospecificity for $(R)$-ibuprofen esters. J. Biotechnol. 2007, 130, 370-377. [CrossRef] [PubMed]

10. Chow, J.; Kovacic, F.; Dall Antonia, Y.; Krauss, U.; Fersini, F.; Schmeisser, C.; Lauinger, B.; Bongen, P.; Pietruszka, J.; Schmidt, M.; et al. The Metagenome-derived enzymes LipS and LipT increase the diversity of known lipases. PLoS ONE 2012, 7, e47665. [CrossRef] [PubMed]

11. Kim, Y.J.; Choi, G.S.; Kim, S.B.; Yoon, G.S.; Kim, Y.S.; Ryu, Y.W. Screening and characterization of a novel esterase from a metagenomic library. Protein Expr. Purif. 2006, 45, 315-323. [CrossRef] [PubMed]

12. Yoon, S.; Kim, S.; Ryu, Y.; Kim, T.D. Identification and characterization of a novel (S)-ketoprofen-specific esterase. Int. J. Biol. Macromol. 2007, 41, 1-7. [CrossRef] [PubMed]

13. Ngo, T.D.; Ryu, B.H.; Ju, H.; Jang, E.J.; Kim, K.K.; Kim, T.D. Crystallographic analysis and biochemical applications of a novel penicillin-binding protein/beta-lactamase homologue from a metagenomic library. Acta Crystallogr. D Biol. Crystallogr. 2014, 70, 2455-2466. [CrossRef] [PubMed]

14. Kim, J.; Seok, S.H.; Hong, E.; Yoo, T.H.; Seo, M.D.; Ryu, Y. Crystal structure and characterization of esterase Est25 mutants reveal improved enantioselectivity toward (S)-ketoprofen ethyl ester. Appl. Microbiol. Biotechnol. 2017, 101, 2333-2342. [CrossRef] [PubMed]

15. Ferrer, M.; Golyshina, O.V.; Chernikova, T.N.; Khachane, A.N.; Martins dos Santos, V.A.P.; Yakimov, M.M.; Timmis, K.N.; Golyshin, P.N. Microbial enzymes mined from the Urania deep-sea hypersaline anoxic basin. Chem. Biol. 2005, 12, 895-904. [CrossRef] [PubMed]

16. Kourist, R.; Hari Krishna, S.; Patel, J.S.; Bartnek, F.; Hitchman, T.S.; Weiner, D.P.; Bornscheuer, U.T. Identification of a metagenome-derived esterase with high enantioselectivity in the kinetic resolution of arylaliphatic tertiary alcohols. Org. Biomol. Chem. 2007, 5, 3310-3313. [CrossRef] [PubMed]

17. Fernández-Álvaro, E.; Kourist, R.; Winter, J.; Böttcher, D.; Liebeton, K.; Naumer, C.; Eck, J.; Leggewie, C.; Jaeger, K.E.; Streit, W.; et al. Enantioselective kinetic resolution of phenylalkyl carboxylic acids using metagenome-derived esterases. Microb. Biotechnol. 2010, 3, 59-64. [CrossRef] [PubMed]

18. Ouyang, L.M.; Liu, J.Y.; Qiao, M.; Xu, J.H. Isolation and biochemical characterization of two novel metagenome-derived esterases. Appl. Biochem. Biotechnol. 2013, 169, 15-28. [CrossRef] [PubMed] 
19. Martini, V.; Glogauer, A.; Muller-Santos, M.; Lulek, J.; de Souza, E.; Mitchell, D.; Pedrosa, F.; Krieger, N. First co-expression of a lipase and its specific foldase obtained by metagenomics. Microb. Cell Factories 2014, 13, 171. [CrossRef] [PubMed]

20. Alnoch, R.C.; Martini, V.P.; Glogauer, A.; Costa, A.C.; Piovan, L.; Muller-Santos, M.; de Souza, E.M.; de Oliveira Pedrosa, F.; Mitchell, D.A.; Krieger, N. Immobilization and characterization of a new regioselective and enantioselective lipase obtained from a metagenomic library. PLoS ONE 2015, 10, e0114945. [CrossRef] [PubMed]

21. Jeon, J.H.; Kim, J.T.; Kang, S.G.; Lee, J.H.; Kim, S.J. Characterization and its potential application of two esterases derived from the arctic sediment metagenome. Mar. Biotechnol. 2009, 11, 307-316. [CrossRef] [PubMed]

22. Elend, C.; Schmeisser, C.; Leggewie, C.; Babiak, P.; Carballeira, J.D.; Steele, H.L.; Reymond, J.L.; Jaeger, K.E.; Streit, W.R. Isolation and biochemical characterization of two novel metagenome-derived esterases. Appl. Environ. Microbiol. 2006, 72, 3637-3645. [CrossRef] [PubMed]

23. Martínez-Martínez, M.; Alcaide, M.; Tchigvintsev, A.; Reva, O.; Polaina, J.; Bargiela, R.; Guazzaroni, M.-E.; Chicote, Á.; Canet, A.; Valero, F.; et al. Biochemical diversity of carboxyl esterases and lipases from Lake Arreo (Spain): A metagenomic approach. Appl. Environ. Microbiol. 2013, 79, 3553-3562. [CrossRef] [PubMed]

24. Alcaide, M.; Tchigvintsev, A.; Martinez-Martinez, M.; Popovic, A.; Reva, O.N.; Lafraya, A.; Bargiela, R.; Nechitaylo, T.Y.; Matesanz, R.; Cambon-Bonavita, M.A.; et al. Identification and characterization of carboxyl esterases of gill chamber-associated microbiota in the deep-sea shrimp Rimicaris exoculata by using functional metagenomics. Appl. Environ. Microbiol. 2015, 81, 2125-2136. [CrossRef] [PubMed]

25. Placido, A.; Hai, T.; Ferrer, M.; Chernikova, T.N.; Distaso, M.; Armstrong, D.; Yakunin, A.F.; Toshchakov, S.V.; Yakimov, M.M.; Kublanov, I.V.; et al. Diversity of hydrolases from hydrothermal vent sediments of the Levante Bay.; Vulcano Island (Aeolian archipelago) identified by activity-based metagenomics and biochemical characterization of new esterases and an arabinopyranosidase. Appl. Microbiol. Biotechnol. 2015, 99, 10031-10046. [CrossRef] [PubMed]

26. Lee, H.W.; Jung, W.K.; Kim, Y.H.; Ryu, B.H.; Kim, T.D.; Kim, J.; Kim, H. Characterization of a novel alkaline family VIII esterase with $S$-enantiomer preference from a compost metagenomic library. J. Microbiol. Biotechnol. 2016, 26, 315-325. [CrossRef] [PubMed]

27. Gao, W.; Fan, H.; Chen, L.; Wang, H.; Wei, D. Efficient kinetic resolution of secondary alcohols using an organic solvent-tolerant esterase in non-aqueous medium. Biotechnol. Lett. 2016, 38, 1165-1171. [CrossRef] [PubMed]

28. Kumar, R.; Banoth, L.; Banerjee, U.C.; Kaur, J. Enantiomeric separation of pharmaceutically important drug intermediates using a metagenomic lipase and optimization of its large scale production. Int. J. Biol. Macromol. 2017, 95, 995-1003. [CrossRef] [PubMed]

29. Böttcher, D.; Zägel, P.; Schmidt, M.; Bornscheuer, U.T. A microtiter plate-based assay to screen for active and stereoselective hydrolytic enzymes in enzyme libraries. Methods Mol. Biol. 2017, 1539, 197-204. [PubMed]

30. Gawley, R.E. Do the terms "\% ee" and “\% de" make sense as expressions of stereoisomer composition or stereoselectivity? J. Org. Chem. 2006, 71, 2411-2416. [CrossRef] [PubMed]

31. Reetz, M.T. (Ed.) Introduction to directed evolution. In Directed Evolution of Selective Enzymes: Catalysts for Organic Chemistry and Biotechnology; Wiley-VCH Verlag GmbH \& Co. KGaA: Weinheim, Germany, 2016; pp. 1-16.

32. Romano, D.; Bonomi, F.; de Mattos, M.C.; de Sousa Fonseca, T.; de Oliveira Mda, C.; Molinari, F. Esterases as stereoselective biocatalysts. Biotechnol. Adv. 2015, 33, 547-565. [CrossRef] [PubMed]

33. Wikmark, Y.; Svedendahl Humble, M.; Bäckvall, J.E. Combinatorial library based engineering of Candida antarctica lipase A for enantioselective transacylation of sec-alcohols in organic solvent. Angew. Chem. Int. Ed. Engl. 2015, 54, 4284-4288. [CrossRef] [PubMed]

(C) 2018 by the authors. Licensee MDPI, Basel, Switzerland. This article is an open access article distributed under the terms and conditions of the Creative Commons Attribution (CC BY) license (http://creativecommons.org/licenses/by/4.0/). 